\title{
COLONIZAÇÃO E NEOCOLONIZAÇÃO DA GESTÃO DE RECURSOS HUMANOS NO BRASIL (1950-2010)
}

COLONIZATION AND NEO-COLONIZATION OF HUMAN RESOURCE MANAGEMENT IN BRAZIL (1950-2010)

COLONIZACIÓN Y NEOCOLONIZACIÓN DE LA GESTIÓN DE

RECURSOS HUMANOS EN EL BRASIL (1950-2010)

\section{RESUMO}

A Gestão de Recursos Humanos (GRH), como campo prático da Administração de Empresas e como área de ensino e pesquisa, desenvolveu-se vigorosamente no Brasil. Este ensaio crítico tem como objetivo apresentar uma análise histórica dessa evolução nos últimos 60 anos. Para isso, caracterizamos e analisamos dois períodos: 19501980, o qual denominamos colonização; e 1980-2010, o qual denominamos neocolonização. Para cada período, apresentamos o contexto político e econômico, as mudanças ocorridas na GRH e o discurso correspondente.
Nossa análise adota a perspectiva do pós-colonialismo, uma corrente de pesquisa ascendente em Estudos Organizacionais, e introduz e utiliza a perspectiva do tropicalismo, uma abordagem genuinamente local, derivada dos movimentos culturais dos anos 1960. Nós argumentamos que a GRH desenvolveu-se no Brasil a partir de um movimento de colonização oriundo do estrangeiro. Tal movimento, envolvendo colonizadores e colonizados, compreendeu assimetrias em termos de poder, porém incluiu também interdependências e recriações.

PALAVRAS-CHAVE Gestão de recursos humanos, gestão de pessoas, pós-colonialismo, tropicalismo, ideologia do management, cultura do management.

Thomaz Wood Jr. thomaz.wood@fgv.br

Professor da Escola de Administração de Empresas de São Paulo, Fundação Getulio Vargas - São Paulo - SP, Brasil

Maria José Tonelli mjtonelli@fgv.br

Professora da Escola de Administração de Empresas de São Paulo, Fundação Getulio Vargas - São Paulo - SP, Brasil

Bill Cooke b.cooke@lancs.ac.uk

Professor da Lancaster University Management School - Lancaster - England

Abstract Human resource management, as a practical field of business administration and as a teaching and research area, has developed vigorously in Brazil. The objective of this critical essay is to present an historical analysis of this evolution over the last 60 years. To do so we characterize and analyze two periods: 1950-1980, which we call colonization; and 1980-2010, which we call neo-colonization. For each period we present the political and economic context, the changes that occurred in human resource management and the corresponding discourse. Our analysis adopts the perspective of post-colonialism, a rising tide in research in organizational studies, and introduces and uses the perspective of tropicalism, a genuinely local approach, which is derived from the cultural movements of the 1960s. We argue that human resource management developed in Brazil from a colonization movement that came from abroad. This movement, which involved both colonizers and colonized, comprised asymmetries in terms of power, but also included interdependence and re-creations.

Keywords Human resource management, people management, post-colonialism, tropicalism, management ideology, management culture.

Resumen La gestión de Recursos Humanos, como campo práctico de la Administración de Empresas, y como área de enseñanza e investigación, se ha desarrollado vigorosamente en el Brasil. Este ensayo crítico tiene como objetivo presentar un análisis histórico de esta evolución en los últimos 60 años. Para eso, caracterizamos y analizamos dos períodos: 1950-1980, el cual denominamos de colonización; y 1980-2010, al que llamamos de neocolonización. Para cada período, nosotros presentamos un contexto político y económico, los cambios ocurridos en la Gestión de los Recursos Humanos, y el discurso correspondiente. Nuestro análisis adopta la perspectiva del Postcolonialismo, una cadena de investigación ascendente en Estudios Organizacionales, e introduce y utiliza la perspectiva del Tropicalismo, un abordaje genuinamente local, derivado de los movimientos culturales de los años 1960. Nosotros argumentamos que la GRH se ha desarrollado en el Brasil a partir de un movimiento de colonización, oriundo del extranjero. Tal movimiento, envolviendo colonizadores y colonizados, comprendió asimetrías en termos de poder, pero incluyó también interdependencias y recreaciones.

Palabras clave Gestión de recursos humanos, gestión de personas, postcolonialismo, tropicalismo, ideología del management, cultura del management. 
Thomaz Wood Jr. - Maria José Tonelli - Bill Cooke

\section{COLONIZAÇÃO E NEOCOLONIZAÇÃO DA GESTÃO DE RECURSOS HUMANOS NO BRASIL (1950-2010)}

\begin{abstract}
Tudo que eu sei da nossa história e da história do Oceano Índico veio de livros escritos por europeus. [...] Sem os europeus, sinto que todo o nosso passado teria se apagado, como as pegadas dos pescadores da praia de nossa cidade. (NAIPAUL, 2004, p. 17)
\end{abstract}

No segundo capítulo do livro Uma curva no rio, escrito pelo ganhador do prêmio Nobel V. S. Naipaul, o comerciante Salim, muçulmano e de origem indiana, revela o pouco apego pela memória e a ausência de sentido histórico de seu povo. Salim retrata os colonizadores europeus a partir de uma perspectiva neutra, quase agradável. Para o leitor, o texto é ambíguo. Os europeus podem ser vistos como os donos da história, a qual moldam segundo a sua própria vontade, ou como os guardiões da memória coletiva, a possibilitar a preservação da identidade de outros povos. Este ensaio inspirase neste trecho do livro de Naipaul para analisar a história da GRH no Brasil.

A GRH, ou Gestão de Pessoas, constitui tanto um campo prático da Administração de Empresas como também uma área de ensino e pesquisa. No Brasil, esse campo prático e essa área de ensino e pesquisa desenvolveram-se vigorosamente nas últimas décadas. Uma pesquisa nos arquivos digitalizados da $R A E$, que, em 2011, completa 50 anos ininterruptos de publicação, tomando o termo recursos humanos como palavra-chave, revela 55 textos. Desses textos, apenas dois foram publicados na década de 1960 e nada menos do que 18 foram publicados na década de 2000, indicando o crescimento da área. Não localizamos, no entanto, trabalhos históricos, de cunho reflexivo, sobre o tema.

Este ensaio procura contribuir para o preenchimento dessa lacuna. Nosso objetivo é apresentar uma avaliação crítica sobre a evolução do campo prático da GRH no Brasil nos últimos 60 anos. Nós argumentamos que a GRH desenvolveu-se no Brasil a partir de um movimento de colonização oriundo do estrangeiro. Esse movimento incluiu a introdução do management, ou managerialism, como ideologia e como conjunto de práticas administrativas, assim como sua renovação, em um movimento neocolonizador.

Para viabilizar nossa análise, consideramos dois períodos: de 1950 a 1980, e de 1980 a 2010. Nós tomamos esses dois períodos em sintonia com os trabalhos de análise da história do Brasil contemporâneo (por exemplo, SKIDMORE, 1998; FAUSTO, 1999). A década de 1950, após a Segunda Guerra Mundial, é marcada pelo processo de modernização do País. A década de 1980, por sua vez, é marcada pelo processo de democratização, a qual abre espaço para a liberalização econômica, ocorrida na década de 1990. Para cada período, mostramos o contexto político e econômico, as mudanças na GRH e o discurso correspondente. Entendemos que o discurso não apenas reflete a realidade mas também pode interferir, construir e até definir a realidade (PHILLIPS e HARDY, 2002).

Este ensaio está estruturado em quatro seções, além desta introdução. As seções seguintes apresentam o desenvolvimento de GRH no Brasil em dois períodos: 1950-1980, o qual denominamos colonização; e 1980-2010, o qual denominamos neocolonização. Em seguida, utilizamos a perspectiva do pós-colonialismo e introduzimos a perspectiva do tropicalismo para discutir sua evolução. A última seção registra as limitações deste trabalho e indica direções para futuras pesquisas.

\section{COLONIZAÇÃO DA GESTÃO DE RECURSOS HUMANOS (1950-1980)}

Nesta seção, trataremos do desenvolvimento da GRH no Brasil, de 1950 a 1980. Mostraremos o contexto político e econômico do período e as mudanças que ocorreram na GRH. Em seguida, caracterizaremos o que denominamos "discurso da colonização".

\section{Contexto político e econômico (1950-1980)}

O período que se seguiu ao fim da Segunda Guerra Mundial foi marcado por forte desenvolvimento econômico em todo o mundo. No Brasil, o governo promoveu a criação de indústrias de base e iniciou 
a implantação de grandes obras de infraestrutura. As empresas multinacionais que já operavam no Brasil investiram maciçamente e novas empresas passaram a investir no País. O modelo norte-americano de desenvolvimento, baseado na produção e no consumo em massa, foi adotado. Esse processo fomentou $\mathrm{o}$ crescimento da classe média, porém não chegou a alcançar as camadas mais pobres da população (BRESSER-PEREIRA, 1962).

O início da década de 1960 foi marcado por uma forte turbulência política interna, a qual culminou com um golpe militar, em 1964. O governo autoritário que assumiu o controle manteve a tradição dos governos anteriores, de forte intervenção estatal na economia. Grandes investimentos em infraestrutura foram feitos, com foco nos setores de energia, telecomunicações e transporte. O modelo de desenvolvimento adotado foi baseado em uma tríade, formada por grandes empresas públicas, grandes empresas multinacionais e grandes empresas privadas nacionais, que operavam em um mercado protegido e controlado pelo Estado (veja SKIDMORE, 1998; FAUSTO, 1999).

De 1950 a 1980, o Brasil atingiu altas taxas de crescimento do Produto Interno Bruto (PIB), alcançando uma média de quase 9\% na década de 1970 (FAUSTO, 1999; ALVES e BRUNO, 2009). Na própria década de 1970, no entanto, a economia seria desestabilizada pela crise do petróleo, criando o que ficou conhecido como a década perdida (a década de 1980), um período marcado pela recessão, pela inflação e pela instabilidade econômica. Em paralelo, o sistema político sofreu fortes pressões para permitir a liberalização, o que culminou com a chamada "abertura democrática" (veja GASPARI, 2003, 2004).

\section{Mudanças na Gestão dos Recursos Humanos (1950-1980)}

O período de 1950 a 1980 foi marcado por importantes mudanças na GRH. Dois agentes tiveram um papel relevantenessas mudanças: asempresas multinacionais e as escolas de administração. As empresas multinacionais foram as principais responsáveis pela introdução, no Brasil, de princípios de divisão do trabalho, de valores relacionados à meritocracia e de práticas de GRH, tais como recrutamento, seleção, treinamento e desenvolvimento. Empresas norteamericanas e europeias, como a General Motors, a Ford e a Volkswagen, tiveram papel de destaque nesse processo (WOOD JR, 2004).
As escolas de administração também tiveram um papel relevante na disseminação de modelos e práticas de GRH. O primeiro curso totalmente focado em negócios e gestão foi criado em 1954, pela Fundação Getulio Vargas (FGV), em São Paulo, com a Escola de Administração de Empresas de São Paulo (EAESP). Um grupo formado por professores da Michigan State University participou da concepção dos programas acadêmicos. Como parte do projeto, professores universitários brasileiros receberam treinamento nos Estados Unidos.

Além dessa nova instituição de ensino criada em São Paulo, foram criadas escolas de administração nos Estados do Rio Grande do Sul, do Rio de Janeiro e da Bahia (WOOD JR. e PAES de PAULA, 2004). Na década de 1960 , a FGV criou o seu primeiro programa de pós-graduação. Isso permitiu que a instituição formasse professores para outras escolas, contribuindo, dessa forma, para a disseminação de novos modelos e práticas de gestão (veja BERTERO, 2006). As instituições de ensino, em conjunto com as consultorias e uma incipiente mídia de negócios (neste período surgiram os primeiros jornais voltados para a área econômica e a Revista Exame) começam a influenciar a dinâmica corporativa brasileira (DONADONE, 2001).

\section{Discurso da colonização}

O período 1950-1980, aqui denominado "colonização", foi caracterizado pela urbanização, industrialização, modernização, e também pela introdução das práticas fundamentais de GRH: recrutamento e seleção, treinamento e desenvolvimento e gestão de carreira.

O discurso da colonização pressupunha que a importação e a implementação de modelos e práticas de GRH desempenharam um papel importante na profissionalização das empresas, na melhoria das práticas administrativas e na modernização das relações de trabalho. Tal discurso está presente nos textos sobre GRH publicados pela $R A E$ neste período (por exemplo, MALFERRARI, 1963; VIEIRA MANSO, 1964; HOYLER, 1965, 1966; ROMAN, 1974; GONÇALVES DE ARAÚJO, 1977). Esses textos podem ser caracterizados como técnicos e supostamente neutros, porém trazem, implicitamente, o pressuposto de que a GRH é uma atividade de base científica, estruturada e sistemática, que constitui um vetor para a modernização da gestão das empresas e para o progresso social. 
Tal concepção é coerente com a visão do management, ou managerialism como ideologia. De acordo com Pollitt (1990), o managerialism é uma ideologia porque constitui um conjunto de crenças e práticas, no centro das quais reside o pressuposto de que sua aplicação efetiva resolverá problemas sociais e econômicos. A ideologia do management permeia os modelos e as práticas de GRH implementados no período, além de prover sustentação para o discurso da colonização.

Essa perspectiva é obviamente positiva e relaciona o processo ocorrido à substituição de relações de trabalho arcaicas, pré-modernas, por práticas mais modernas. Segundo tal ponto de vista, os modelos e práticas importados por empresas multinacionais e pelas escolas de administração trouxeram benefícios para as organizações, as quais puderam aumentar a sua eficiência operacional. Eles também trouxeram vantagens para os trabalhadores diretamente envolvidos, que passaram a ter acesso a vários benefícios, incluindo os programas de saúde e os programas de formação e de desenvolvimento. Por isso, para parte da força de trabalho que antes era submetida a condições precárias de emprego, a experiência de mudança foi positiva (LACOMBE, TONELLI e CALDAS, 2007). O discurso da colonização também advogava que o movimento teve um impacto social positivo, estimulando a criação de uma camada de gestores antes não existente, e ajudando a fomentar a emergência da classe média local (BRESSER-PEREIRA, 1962).

\section{NEOCOLONIZAÇÃO DA GESTÃO DE RECURSOS HUMANOS (1980-2010)}

Discutiremos, nesta seção, o período 1980-2010. Inicialmente, mostraremos o contexto político e econômico. Em seguida, comentaremos as mudanças na GRH. Como na seção anterior, finalizaremos esta parte do ensaio identificando o discurso dominante, neste caso denominado discurso da "neocolonização".

\section{Contexto político e econômico (1980-2010)}

A década de 1970, embora tenha sido caracterizada por elevadas taxas de desenvolvimento econômico, ampliou as enormes desigualdades sociais existentes (FURTADO, 2007). A década de 1980, após a crise do petróleo ocorrida na década anterior, acrescentou a esse problema a estagnação econômica e o desemprego.

Na década de 1980, ocorreu também a transição do governo militar para o regime democrático, o que abriu espaço, na década seguinte, para um profundo processo de reformas econômicas (veja FAUSTO, 1999; FISHLOW, 2004). A partir da primeira metade da década de 1990, foram implementadas mudanças que incluíram medidas baseadas nos princípios do neoliberalismo: a disciplina fiscal; o direcionamento dos fundos públicos ao financiamento da educação básica e dos cuidados primários de saúde, e ao investimento em infraestrutura; a garantia dos direitos de propriedade; a desregulamentação da economia; a privatização; a redução das barreiras ao investimento estrangeiro e a liberalização financeira (BAUMANN, 2002).

Para as empresas, a década de 1990 foi um período de adaptação ao novo contexto competitivo, caracterizada pela adoção de programas de redução de custos, por revisões de portfólios de negócios, pela adoção de novas tecnologias de produção e por esforços de modernização da gestão (WOOD JR. e CALDAS, 2002). Em decorrência disso, houve significativa importação de expertise gerencial. Empurradas pela concorrência, as empresas investiram fortemente na formação dos seus funcionários e na implantação de novas práticas de gestão. Elas também buscaram alterar o que consideravam ser uma cultura corporativa anacrônica, caracterizada pela alta distância do poder, pelo nível insuficiente de cooperação e comunicação interna, pela falta de iniciativa e pela postura de espectador de seus quadros profissionais (veja TANURE, 2005).

O movimento das empresas na busca por eficiência gerou também uma forte demanda por quadros qualificados, atendida, entretanto, apenas por uma parcela dos profissionais, os quais detinham as competências necessárias. Como consequência da falta de investimentos em educação no período anterior, as empresas passam a enfrentar, especialmente a partir da virada do século XX, dificuldades no preenchimento das posições de trabalho que exigiam maior qualificação. Com isso, taxas ainda significativas de desemprego passaram a conviver com postos não preenchidos, freando a redução da desigualdade social (veja BALASSIANO e COSTA, 2006).

As mudanças na economia e nas empresas foram seguidas pelo notável desenvolvimento da chamada 
indústria do management, formada pelas escolas de administração, pelas empresas de consultoria, pelos editores de livros e revistas de negócios e pelas empresas promotoras de seminários empresariais (MICKLETHWAITE e WOOLDRIDGE, 1997; WOOD JR. e PAES de PAULA, 2008). De fato, a expressão management foi incorporada ao léxico corporativo. Tal conceito transcende as técnicas de gestão, caracterizando-se por um conjunto de conhecimentos, valores e comportamentos que marca o processo de modernização do século XX (VIZEU, 2008; WOOD JR. e PAES DE PAULA, 2008). Esse processo ganhou força após a Segunda Guerra Mundial, em função do vitorioso modelo americano, que se estendeu por todo o mundo.

No período 1980-2010, o número de programas de graduação em administração de empresas aumentou de modo acelerado, atingindo a impressionante marca de 2000 programas já no final da década de 1990 (BERTERO, 2006). Os programas de MBA e de educação executiva também cresceram substancialmente, em conjunto com as universidades corporativas, criadas por grandes empresas estatais, por empresas multinacionais e por empresas privadas nacionais. As oportunidades comerciais decorrentes da privatização, os processos de reestruturação, de fusões e aquisições atraíram grandes empresas de consultoria para o Brasil e impulsionaram o crescimento daquelas que aqui já operavam. A imprensa especializada em negócios cresceu e prosperou em torno do novo credo, defendendo a globalização e o livre mercado, e promovendo novas ideias de gestão. Várias revistas e jornais de negócios foram lançados na década de 1990 (DONADONE, 2001; RUMBLESPERGER, 2011) As redes de TV também investiram no novo nicho, lançando programas que discutiam negócios, gestão e empreendedorismo. Finalmente, empresas especializadas em eventos corporativos se estabeleceram, trazendo os mais famosos gurus de gestão para o Brasil (COOKE, MACAU e ALMEIDA, 2007).

A última década deste segundo período foi marcada pelo crescimento econômico, favorecido pela conjuntura externa favorável, com a exceção provocada pela crise financeira do final da década. O modelo econômico criado nas décadas anteriores foi preservado. No mundo corporativo, as empresas continuaram suas iniciativas de modernização, envolvendo fusões e aquisições, reestruturações e investimentos em tecnologia e em novas práticas de gestão.

\section{Mudanças na Gestão dos Recursos Humanos (1980-2010)}

O período 1980-2010 foi marcado por três grandes mudanças na GRH. A primeira relacionou-se com a busca de um melhor alinhamento com os objetivos empresariais (BERTERO, 1982). No período anterior, a área de GRH, mais frequentemente denominada departamento de pessoal, tinha um papel operacional, com participação limitada nos principais processos de tomada de decisão. No período 1980-2010, a GRH tornou-se estrategicamente importante para as empresas. Para responder às demandas empresariais, as áreas de GRH adotaram estruturas descentralizadas, criando postos de trabalho para consultores internos, com atuação na linha de frente dos negócios. Consequentemente, suas prioridades passaram a ser determinadas diretamente pelas demandas dos negócios.

A segunda grande mudança diz respeito à adoção intensiva de novos modelos e práticas. A área de GRH tornou-se uma porta de acesso fácil para modas e modismos gerenciais (ABRAHAMSON, 1996). Head hunters, profissionais especializados em selecionar executivos, com novos e sofisticados métodos de avaliação, tornaramse obrigatórios nos processos de seleção de pessoal qualificado para a alta gestão. Áreas de treinamento e desenvolvimento expandiram suas atividades, adotando frequentemente o rótulo de universidades corporativas. Áreas de gestão de carreira adotaram novos métodos de avaliação, passando a classificar funcionários de acordo com matrizes de desempenho. Para desenvolver a liderança, um conceito que se tornou o novo fetiche do ambiente corporativo (SIEVERS, 1993), as áreas de GRH começaram a utilizar as práticas de coaching e mentoring. Tais expressões, em inglês, foram incorporadas à linguagem cotidiana das empresas. Finalmente, as áreas de GRH passaram a promover a adoção de códigos de ética e de políticas de responsabilidade social e diversidade.

A terceira grande mudança diz respeito à adoção de uma nova retórica. Em paralelo com as mudanças acima mencionadas, a área de GRH adotou um novo discurso, caracterizado pela presença de valores individualistas relacionados ao sucesso e à excelência, ao culto dos líderes transformacionais e à promoção dos princípios de adaptabilidade, 
inovação e competitividade. Tal discurso materializou-se, com frequência, em projetos de intervenção cultural, que buscaram promover comportamentos e valores sintonizados com o contexto de negócios e o espírito da época.

Como vimos, a última década do período foi marcada, em geral, por vigoroso crescimento econômico, o que aumentou a pressão para a modernização das práticas de GRH. Diante de tal pressão e de variada oferta de soluções, disponibilizadas por empresas de consultoria, escolas de administração e assessorias diversas, as empresas aumentaram a contratação de programas de desenvolvimento e de projetos de implementação de novas práticas e de novos sistemas.

Essas mudanças foram discutidas em seminários e conferências (por exemplo, o CONARH), com a participação de milhares de profissionais. Várias revistas especializadas surgiram para promover o progresso e as realizações dos profissionais de GRH. Alguns estudos (por exemplo CURADO, PEREIRA FILHO E WOOD JR, 1995, 1996; LACOMBE e TONELLI, 2001) sugerem, no entanto, que essas mudanças foram realizadas em apenas uma pequena parte das empresas. Em geral, as mais engajadas foram as grandes empresas: enquanto as grandes multinacionais, as empresas estatais e as grandes empresas privadas brasileiras emulavam modelos e práticas vindos do exterior, a maioria das empresas de médio e pequeno porte ainda não contava nem mesmo com as funções básicas de GRH.

\section{Discurso da neocolonização}

Este segundo período, o qual denominamos "neocolonização", foi marcado por reformas liberalizantes, pela renovação da ideologia do management e pela adoção maciça de novos modelos e práticas de GRH. Um novo discurso acompanhou esse período, oferecendo uma visão renovada para a GRH.

A atuação conjunta das empresas de consultoria, das escolas de administração, das editoras de livros e revistas de negócios e das empresas promotoras de eventos ajudou a difundir novos modelos e práticas de gestão, inclusive de GRH. Tal ação também ajudou a disseminar a cultura do management, base do discurso da neocolonização.

A cultura do management é um conjunto de pressupostos compartilhados pelas empresas e pela sociedade, que incluem: (a) a crença no livre mercado; (b) uma visão das pessoas como empresários de si mesmos; (c) a percepção da gestão como um meio para a excelência individual e a melhoria coletiva; (d) a utilização maciça de símbolos e palavras-chave relacionados ao management (por exemplo, inovação, sucesso e excelência); e (e) a convicção de que os conhecimentos de gestão permitem a otimização das atividades organizadas (WOOD JR. e PAES de PAULA, 2008; RUMBLESPERGER, 2011). A cultura do management renovou a ideologia do management, citada na seção anterior.

O discurso da neocolonização é permeado pela premissa de inclusão do Brasil na moderna economia do conhecimento, um sistema aberto e global. Em suas variadas manifestações, na academia e no mundo corporativo (veja, por exemplo, as revistas Você S.A., Você RH, HSM Management e Melhor) esse discurso promove a "nova ordem econômica", a abertura do mercado, o empreendedorismo, a concorrência e a busca permanente de inovação, da qualidade e da eficiência.

Tal discurso está também presente, de maneira mais austera, nos textos sobre GRH publicados pela $R A E$ neste segundo período (por exemplo, FISCHER, 1991; SILVA GUTIERREZ, 1991; RIBEIRO DE ALMEIRA, TEIXEIRA e MARTINELLI, 1993; FLEURY, 1993, 2000; RHINOW, 2001; SANTOS DE CASTRO, 2005). Esses textos refletem as mudanças na GRH ocorridas no período, introduzindo novos temas, ressaltando a importância das mudanças e retratando o alinhamento das políticas e práticas de GRH com a estratégia de negócios.

Nas empresas, esse novo discurso e um tipo emergente de literatura (por exemplo PETERS e WATERMAN, 1982; PINCHOT III, 1985; ULRICH, SMALLWOOD e SWEETMAN, 2009; CHARAN, DROTTER e NOEL, 2010) passaram a fornecer a retórica e as ferramentas para as mudanças. Tal literatura também promoveu a disseminação de um conhecimento gerencial marcado por modas e modismos (ABRAHAMSON, 1996), denominado "pop management" (WOOD e PAES DE PAULA, 2002, 2004, 2008).

\section{DISCUSSÃO}

Nas seções precedentes, apresentamos um retrato do desenvolvimento da GRH no Brasil em dois períodos, 1950-1980 e 1980-2010. Procuramos localizar tal movimento no contexto de mudanças mais amplas 
ocorridas no País. O Quadro 1 sintetiza as informações dos dois períodos. Nesta seção, apresentaremos uma reflexão crítica. Para isso, adotaremos a perspectiva do pós-colonialismo, que complementaremos com a perspectiva do tropicalismo. minação. Segundo Prasad (2003), o pós-colonialismo pressupõe a existência de uma complexa constelação de práticas inter-relacionadas, que pretende estabelecer a hegemonia ocidental política, econômica e militarmente, e também cultural e ideologicamente.

\section{Quadro 1 - Características dos dois períodos}

\begin{tabular}{|c|c|c|}
\hline Características & $\begin{array}{l}\text { 1950-1980 } \\
\text { COLONIZAÇÃO }\end{array}$ & $\begin{array}{c}1980-2010 \\
\text { NEOCOLONIZAÇÃO }\end{array}$ \\
\hline $\begin{array}{l}\text { Contexto político } \\
\text { e econômico }\end{array}$ & $\begin{array}{l}\text { Aceleração do processo de industrialização, com interven- } \\
\text { ção do Estado, atingindo com maior força a região sudeste } \\
\text { Passagem de uma economia predominantemente } \\
\text { agrícola para uma economia industrial } \\
\text { Forte processo de urbanização, com a emergência } \\
\text { de uma classe média urbana } \\
\text { Existência de grandes desigualdades sociais e regionais }\end{array}$ & $\begin{array}{l}\text { Crescimento do setor de serviços, especialmente } \\
\text { nos grandes centros urbanos } \\
\text { Adoção de políticas econômicas baseadas no } \\
\text { Consenso de Washington: redução do papel do } \\
\text { Estado e liberalização econômica } \\
\text { Manutenção de grandes desigualdades sociais } \\
\text { e regionais, com uma inversão de tendência } \\
\text { na última década do período }\end{array}$ \\
\hline $\begin{array}{l}\text { Contexto de } \\
\text { negócios }\end{array}$ & $\begin{array}{l}\text { Modelo baseado no tripé: grandes empresas de } \\
\text { propriedade estatal, grandes empresas multinacionais } \\
\text { e grandes empresas brasileiras de propriedade } \\
\text { privada, operando em um mercado protegido }\end{array}$ & $\begin{array}{l}\text { Crescimento dos investimentos estrangeiros } \\
\text { e das privatizações } \\
\text { Crescimento das fusões e aquisições, das } \\
\text { reestruturações e dos processos de terceirização }\end{array}$ \\
\hline $\begin{array}{l}\text { Agentes de } \\
\text { difusão }\end{array}$ & $\begin{array}{l}\text { Estado, organizações de formação (por exemplo: IDORT) } \\
\text { e escolas de administração }\end{array}$ & $\begin{array}{l}\text { Escolas de administração, serviços de consultoria, } \\
\text { editoras de livros e revistas, empresas promotoras } \\
\text { de eventos corporativos com gurus e associações } \\
\text { profissionais (por exemplo: ABRH) }\end{array}$ \\
\hline $\begin{array}{l}\text { Características } \\
\text { da GRH }\end{array}$ & $\begin{array}{l}\text { Disseminação dos departamentos de pessoal, } \\
\text { orientados para cumprir as leis trabalhistas } \\
\text { Divulgação do núcleo básico de práticas de GRH, } \\
\text { sob liderança das empresas multinacionais }\end{array}$ & $\begin{array}{l}\text { Crescente demanda por trabalhadores qualificados, } \\
\text { devido à abertura do mercado e à introdução de } \\
\text { novas tecnologias } \\
\text { Disseminação da GRH estratégica, sob a liderança } \\
\text { das empresas multinacionais } \\
\text { Novas técnicas e nova retórica }\end{array}$ \\
\hline $\begin{array}{l}\text { Elementos-chave } \\
\text { do discurso }\end{array}$ & $\begin{array}{l}\text { Desenvolvimento, nacionalismo, dirigismo, } \\
\text { gestão científica }\end{array}$ & $\begin{array}{l}\text { Gerencialismo, individualismo, empreendedorismo, } \\
\text { livre iniciativa }\end{array}$ \\
\hline
\end{tabular}

\section{Pós-colonialismo e tropicalismo}

O pós-colonialismo é uma perspectiva crítica ascendente no campo de estudos organizacionais (veja, por exemplo, COOKE, 2004; PRASAD, 2005; DAR e COOKE, 2008; FRENKEL e SHENHAV, 2003, 2006; IBARRA-COLADO, 2006). Tal perspectiva centra-se nas relações de influência e dominação entre países desenvolvidos e países em desenvolvimento. O póscolonialismo procura desvendar o etnocentrismo do pensamento hegemônico ocidental, denunciando a sua falsa neutralidade e o seu papel no processo de do-
Tal condição tem implicações sobre a forma como gerenciamos e analisamos as organizações.

Nós acreditamos que o pós-colonialismo nos ajuda a compreender a transferência de modelos e práticas de GRH dos Estados Unidos (um país hegemônico) para o Brasil (um país em desenvolvimento, porém ainda periférico). Pensamos, no entanto, que essa perspectiva deve ser complementada pela perspectiva do tropicalismo. Neste artigo, utilizamos o conceito de tropicalismo com um significado específico, relacionado a um contexto social e cultural. 
O termo tropicalismo foi popularizado no final dos anos 1960 no Brasil. Naquela época, enquanto os países desenvolvidos viviam um período de turbulência social e cultural, o Brasil era governado por um regime militar conservador (veja GASPARI, 2002). Apesar do ambiente hostil, surgiu na música (por exemplo, Os mutantes, Tom Zé e Gilberto Gil), no cinema (por exemplo, Glauber Rocha), no teatro (por exemplo, José Celso Martinez Correa) e nas artes plásticas (por exemplo, Hélio Oiticica) um vigoroso movimento de renovação cultural, que recebeu o nome de tropicalismo ou tropicália.

A música criada nesse período representou uma ruptura com estilos anteriores, como a Bossa Nova e o Samba (veja VASCONCELOS e KIRSCHBAUM, 2007). Ela sintetizava influências da Grã-Bretanha e dos Estados Unidos, entre outras, com raízes e tendências locais. O resultado foi uma música vanguardista, descontraída, irônica e centrada em questões comportamentais. Esse movimento cultural permaneceu até a década de 1970 e deixou fortes influências sobre a cultura e a identidade brasileira.

Acreditamos que, a fim de utilizar o tropicalismo como um referencial teórico, é preciso definir seus contornos e suas características, diferenciando-o do pós-colonialismo. O tropicalismo pode ser visto como herdeiro da antropofagia. Ambos são movimentos que ajudaram a fomentar a identidade brasileira, ambos utilizaram a arte como uma forma de expressão e ambos têm o estrangeiro como um personagem central. Em ambos os casos, também, a relação com o estrangeiro é ambígua, marcada por admiração, fascínio e respeito, mas também por desconfiança e ironia (CALDAS e WOOD JR, 1997). O pós-colonialismo pressupõe a existência da dominação, e a busca de hegemonia política, militar, econômica, cultural e ideológica. O tropicalismo pode ser entendido como um movimento de resistência e de coexistência. $\mathrm{O}$ tropicalismo não nega o processo de dominação, porém aceita as influências com o "coração aberto". De fato, os tropicalistas apreciavam e cultivavam a permeabilidade às idéias e práticas vindas do estrangeiro. Sustentavam, no entanto, que essas ideias e práticas deveriam ser assimiladas de maneira seletiva. Além disso, o tropicalismo utiliza o humor, a ironia e a dissimulação para lidar com as influências externas.

$\mathrm{Na}$ antropofagia e no tropicalismo, o resultado do encontro entre o local e o estrangeiro é uma síntese, materializada em artefatos culturais: livros, pinturas e canções que misturam influências internas e externas, e criam algo novo, muitas vezes inovador. Acreditamos que essa síntese ocorreu na GRH nos dois períodos: 1950-1980 e 1980-2010.

\section{Dinâmica da colonização e da neocolonização}

Processos de colonização têm início com os interesses políticos e econômicos de agentes coloniais, podendo ser países ou grupos dentro dos países. No Brasil, nos primeiros passos da colonização moderna, após a Segunda Guerra Mundial, Nelson Rockefeller foi uma figura chave, que uniu os interesses políticos do governo dos Estados Unidos com os interesses econômicos das empresas norte-americanas (veja TOTA, 2000; CALDAS e ALCADIPANI, 2005).

Nas décadas de 1980 e 1990, não houve figura semelhante. Algumas instituições internacionais, entretanto, como o Banco Mundial e o Fundo Monetário Internacional, tiveram papel parcialmente similar. Os interesses externos alinharam-se com os interesses da elite local, que percebeu vantagens no processo de colonização. O primeiro passo do processo ocorreu, portanto, fora do País, com o esboço de uma estratégia para influenciar e induzir certas mudanças. Esse passo foi seguido por um segundo passo, no qual a elite local, ou parte dela, alinhou seus interesses com aqueles dos colonizadores. O produto foi uma primeira síntese de interesses entre colonizadores e colonizados.

Em seguida, agentes e recursos foram mobilizados para o processo de colonização. No Brasil, essa mobilização envolveu investimentos diretos, programas de assistência tecnológica, iniciativas educacionais e atividades culturais. Enquanto algumas atividades práticas davam substância ao processo colonizador, atividades simbólicas conduziam a nova ideologia, ou a renovação da ideologia existente.

Especificamente quanto à GRH, no primeiro período (1950-1980) a colonização se deu pela transmissão de conhecimento para as escolas de administração, e dessas para os alunos, futuros executivos, e pela importação de modelos e práticas pelas empresas multinacionais. Já no segundo período (1980-2010), a neocolonização se deu pela ação dos componentes da indústria do management: empresas de consultoria, escolas de administração, editoras de livros e revistas de negócios e empresas promotoras de eventos.

Esse processo, no entanto, não ocorreu facilmente. Como qualquer outro processo de transformação, ele enfrentou resistências. No encontro contínuo entre colonizador e colonizado, o conteúdo e os significados trazidos pelo colonizador foram reconhecidos, analisados e transformados. Nesta microdinâmica da colonização, que aconteceu em cada momento do encontro, a ideologia, os modelos e as práticas trazidos pelo colonizador foram avaliados 
e testados. As reações dos colonizados foram variadas. Alguns modelos e práticas foram prontamente negados, considerados inadequados às condições locais. Outros foram aprovados e adotados de maneira cerimonial, para responder às pressões institucionais, mas sem alterações substantivas. Outros foram absorvidos, transformados e utilizados (veja CALDAS e WOOD JR, 1997). Devemos, com isso, reconhecer que o fenômeno que estamos analisando não se caracteriza por eventos discretos, separados, mas por coexistências, simultaneidades e codependências. Em suma, caracteriza-se como um todo dentro do qual há assimetrias em termos de poder, porém há também interdependência e recriação mútua.

\section{Discurso anticolonização}

Ao examinar os artigos sobre GRH e temas afins publicados pela $R A E$, notamos que, a partir da década de 1980 e nas décadas seguintes, foram publicados artigos que se contrapunham ao discurso dominante da colonização (por exemplo, PRESTES MOTTA, 1981, 1984; 2001; FREITAS, 2001; STEPHEN, 2001; ALVES e GALEÃO-SILVA, 2004). Tais artigos ofereciam uma perspectiva alternativa e crítica, a qual denominamos discurso anticolonização. Esse discurso, tal qual manifesto nos artigos, nem sempre se colocava de maneira explícita contra a colonização, porém estabelecia diversas frentes de crítica aos pressupostos da ideologia do management, ou managerialism (POLLITT, 1990), e suas manifestações nas organizações. Essa abordagem crítica caracterizou o trabalho de diversos professores da EAESP, com destaque para Fernando Prestes Motta, Ramon Garcia e Mauricio Tragtenberg, que passaram a influenciar a formação de muitos pesquisadores e professores (PAES DE PAULA, 2008).

O discurso anticolonização, no período 1980-2010, caracterizou-se pela análise dos aspectos negativos da vida corporativa. Tal discurso denunciava o controle social por meio da cultura organizacional, investigava os mecanismos de poder nas organizações e chamava a atenção para o estresse e o assédio moral, condições supostamente aguçadas pela nova ordem. Em diversos artigos, publicados no exterior e no Brasil, o culto do individualismo, a competitividade e o sucesso a qualquer custo foram considerados nocivos e responsáveis pela corrosão do caráter do indivíduo e pela deterioração das relações interpessoais (veja SENNET, 2004; BAUMAN, 1998, 1999; ANTUNES, 1999).

No Brasil, como em outros países, o discurso anti- colonização encontrou espaço apenas no mundo acadêmico, tendo se mantido distante da prática cotidiana das empresas e da esfera do ensino de gestão. O EnANPAD, congresso que catalisa e sintetiza as discussões acadêmicas sobre gestão no País, conta, há muitos anos, com a presença de autores críticos nas divisões de Comportamento Organizacional, Teoria Organizacional e Gestão de Pessoas, entre outras (por exemplo, FARIA, 1985a e 1985b, 2004; DAVEL e ALCADIPANI, 2003; ALCADIPANI, 2005; MISOSCKY e AMANTINO-DE-ANDRADE, 2005; PAES DE PAULA, 2008). Tal grupo tem se mantido como um pequeno núcleo reflexivo, internamente diversificado, com relacionamento com grupos similares no exterior, porém afastado das práticas empresariais e pouco influente sobre a vida organizacional.

\section{CONCLUSÃO}

Neste ensaio, procuramos analisar a evolução histórica da GRH no Brasil. Advogamos que tal processo pode ser dividido em dois períodos: o primeiro (1950-1980), que denominamos colonização; e o segundo (19802010), que denominamos neocolonização. Para cada período, indicamos o contexto político e econômico, as mudanças na GRH e o discurso correspondente. $\mathrm{Na}$ discussão, propusemos a adoção da perspectiva póscolonialista e da perspectiva do tropicalismo.

Acreditamos que este ensaio traz duas contribuições para os estudos da GRH: primeiro, por realizar uma análise histórica crítica da GRH no Brasil; segundo, por colaborar para o desenvolvimento dos estudos pós-coloniais aplicados ao caso de um país emergente, portanto não hegemônico.

Por outro lado, devemos registrar os limites deste trabalho, que podem originar futuros desenvolvimentos. Naturalmente, é preciso reconhecer a ambição, talvez excessiva, de descrever em um ensaio a evolução da GRH em um país continental ao longo de parte considerável do século XX. Acreditamos, no entanto, que o texto representa um esforço inicial de delineamento do objeto e de criação de uma abordagem pertinente.

Certamente, novas iniciativas de pesquisa serão necessárias para complementar tal esforço. Sugerimos duas possibilidades de desenvolvimento: primeiro, aprofundar a investigação histórica nos dois períodos, colhendo mais evidências, por meio da coleta e análise de documentos e de outros dados secundários; segundo, realizar estudos de casos com empresas que passaram por mudanças, especialmente na onda neocolonizadora, a mais recente, visando 
desvendar a microdinâmica da colonização, as manifestações de resistência e as "sínteses criativas tropicalistas".

Nós desejamos que este esforço inicial possa encorajar outros pesquisadores a dar continuidade à tarefa de melhor compreender a realidade local. Tal compreensão nos parece fundamental para a evolução tanto das práticas de GRH quanto do campo correspondente de ensino e pesquisa.

\section{REFERÊNCIAS}

ABRAHAMSON, E. Management fashion. Academy of Management Review, v. 21, n. 1, p. 254-285, 1996.

ALCADIPANI, R. Réplica: a singularização do plural. Revista de Administração Contemporânea, v. 9, n.1, p. 213-222, 2005.

Alves, J. E. D; BRUNO, M. A. P. População e crescimento econômico de longo prazo no Brasil: como aproveitar a janela de oportunidade demográfica. Disponível em: http://www.ie.ufrj.br/datacenterie/pdfs/seminarios/ pesquisa/texto1311.pdf. Acesso em 21.02.2009.

ALVES, M. A; GALEÃO-SILVA, L. G. A crítica da gestão da diversidade nas organizações. RAE-revista de administração de empresas, v. 44, n. 3, p. 20-29, 2004.

ANTUNES, R. Os sentidos do trabalho: ensaios sobre a afirmação e a negação do trabalho. São Paulo: Boitempo, 1999.

BALASSIANO, M; COSTA, I. S. A (Org) Gestão de carreiras: dilemas e perspectivas. São Paulo: Atlas, 2006.

BAUMAN, Z. Work, consumerism and the new poor. Buckingham: Open University Press, 1998.

BAUMAN, Z. Globalização: as consequências humanas. Rio de Janeiro: Jorge Zahar Editor, 1999.

BAUMANN, R. Brazil in the 1990's: an economy in transition. Basingstoke: Palgrave Macmillan, 2002.

BERTERO, C. O. O administrador de recursos humanos e o planejamento empresarial. RAE-revista de administração de empresas, v. 22, n. 1, p. 5-13, 1982.

BERTERO, C. O. Ensino e Pesquisa em Administração. São Paulo: Thomson, 2006.

BRESSER-PEREIRA, L. C. The rise of middle class and middle management in Brazil. Journal of Inter-American Studies, v. 4, p. 313-26, 1962.
BRESSER-PEREIRA, L. C. Democracia, estado social e a reforma gerencial. RAE-revista de administração de empresas, v. 50, n. 1, p. 112-116, 2010.

CALDAS, M. P; ALCADIPANI, R. (North)-Americanizing Latin America: a post-colonialist account of the Americanization of Brazilian management. In: Proceedings of the Iberoamerican Academy of Management, Lisbon, Portugal, 2005.

CALDAS, M. P; WOOD JR, T. For the English to see: the importation of managerial technology in late 20th century Brazil. Organization, v. 4, p. 517-34, 1997.

CHARAN, R; DROTTER, S; NOEL, J. Pipeline de liderança: o desenvolvimento de líderes como diferencial competitivo. Rio de Janeiro: Campus, 2010.

COOKE, B. The management of the (third) world. Organization, v. 11, n. 4, p. 589-615, 2004.

COOKE, B; MACAU, F; ALMEIDA, C. Management gurus self images: an exploratory study. In: ENCONTRO NACIONAL DA ASSOCIAÇÃO DOS PROGRAMAS DE PÓS-GRADUAÇÃO EM ADMINISTRAÇÃO, 31, 2007, RiO de Janeiro. Anais. Rio de Janeiro: ANPAD, 2007.

CURADO, I. B; PEREIRA FILHO, J. L; WOOD JR, T. A gestão de recursos bumanos na grande São Paulo. São Paulo: SENAC, 1995.

CURADO, I. B; PEREIRA FILHO, J. L; WOOD JR, T. A gestão de recursos bumanos no interior de São Paulo. São Paulo: SENAC, 1996.

DAR, S; COOKE, B. (Ed) The new development management. London: Zed Books, 2008.

DAVEL, E; ALCADIPANI, R. Estudos críticos em Administração: a produção científica brasileira nos anos 90. RAE-revista de administração de empresas, v. 43, n. 4, p. 72-85, 2003.

DONADONE, J. C. Os hunos já chegaram: dinâmica organizacional, difusão de conceitos gerenciais e a atuação das consultorias. 2001. Tese de Doutorado apresentada à Escola Politécnica de São Paulo, Departamento de Engenharia de Produção, São Paulo, 2001.

FARIA, J. H. O autoritarismo nas organizações. Curitiba: Criar, 1985a.

FARIA, J. H. Relações de poder e formas de gestão. Curitiba: Criar, 1985b. 
FARIA, J. H. Economia Politica do Poder. Curitiba: Juruá, 2004. 3 v.

FAUSTO, B. A concise history of Brazil. New York: Cambridge University Press, 1999.

FISCHER, R. M. Gestão do trabalho: dimensões institucionais e organizacionais. RAE-revista de administração de empresas, v. 31, n. 4, p. 85-90, 1991.

FISHLOW, A. Desenvolvimento no Brasile na América Latina: uma perspectiva histórica. São Paulo: Paz e Terra, 2004.

FLEURY, M. T. Cultura da qualidade e mudança organizacional. RAE-revista de administração de empresas, v. 33, n. 2, p. 26-34, 1993.

FLEURY, M. T. Gerenciando a diversidade cultural: experiências de empresas brasileiras. RAE-revista de administração de empresas, v. 40, n. 3, p. 18-25, 2000.

FREITAS, M. E. Assédio moral e assédio sexual: faces do poder perverso nas organizações. RAE-revista de administração de empresas, v. 41, n. 2, p. 8-19, 2001.

FRENKEL, M; SHENHAV, Y. From Americanization to colonization: the diffusion of productivity models revisited. Organization Studies, v. 24, n. 9, p. 1537-1561, 2003.

FRENKEL, M; SHENHAV, Y. From Binarism back to Hybridity: a postcolonial reading of Management and Organization Studies. Organization Studies, v. 27, n. 6, p. 855-876, 2006.

FURTADO, C. Formação Econômica do Brasil. São Paulo: Companhia das Letras, 2007.

GASPARI, E. A ditadura escancarada. São Paulo: Schwarcs, 2002.

GASPARI, E. A ditadura derrotada. São Paulo: Schwarcs, 2003.

GASPARI, E. A ditadura encurralada. São Paulo: Schwarcs, 2004.

GONÇALVES DE ARAÚJO, L. C. Organização e métodos: uma opção a mais para o desenvolvimento de recursos humanos. RAE-revista de administração de empresas, v. 17, n. 4, p. 60-62, 1977.

HOYLER, S. Auditoria de pessoal. RAE-revista de administração de empresas, v. 5, n. 17, p. 149-168, 1965.

HOYLER, S. A avaliação sistemática de desempenho de pessoal. RAE-revista de administração de empresas, v. 5, n. 15 , p. 14-40, 1966.
IBARRA-COLADO, E. Organization Studies and epistemic coloniality in Latin America: thinking otherness from the margins. Organization, v. 13, n. 4, p. 463-488, 2006.

LACOMBE, B. M; TONELLI, M. J. O discurso e a prática: O que nos dizem os especialistas e o que nos mostram as práticas das empresas sobre os modelos de gestão de recursos humanos. Revista de Administração Contemporânea, v. 5, n. 2, p. 157-174, 2001.

LACOMBE, B. M, TONELLI, M. J; CALDAS, M. P. GRH in developing countries: does the functionalist vs. critical debate makes sense south of the Equator? Paper presented at Sub-theme 33: Critical approaches to IGRH, EGOS Coloquium, 2007.

MALFERRARI, C. J. Funções e posição da Administração de Pessoal. RAE-revista de administração de empresas, v. 3, n. 6, p. 13-26, 1963.

MICKLETHWAITE, J; WOOLDRIDGE, A. The witchdoctors: what the management gurus are saying, and how to make sense of it. London: Mandarin, 1997.

MISOSCZKY, M. C, AMANTINO-DE-ANDRADE, J. Uma crítica à critica domesticada nos estudos organizacionais. Revista de Administração Contemporânea, v. 9, n. 1, p. 193-211, 2005.

NAIPAUL, V. S. Uma curva no rio. São Paulo: Schwarcz, 2004.

PAES DE PAULA, A. P. Teoria Crítica (em estudos organizacionais). São Paulo: Thomson Learning, 2008.

PETERS, T; WATERMAN JR, R. H. In search of excellence: lessons from America's best run companies. New York: Harper \& Row, 1982.

PHILLIPS, N; HARDY, C. Discourse analysis: investigating processes of social construction. Thousand Oaks: Sage, 2002.

PINCHOT III, G. Intrapreneuring: why you don't have to leave the corporation to become an entrepreneur. New York: Harper \& Row, 1985.

POLLITT, C. Managerialism and the public services. Oxford: Basil Blackwell, 1990.

PRASAD, A. (Ed) Post colonial theory and organizational analysis: a critical engagement. New York: Palgrave Macmillan, 2003.

PRASAD, P. Crafting qualitative research: working in the postpositivist traditions. New York: M. E. Sharpe, 2005. 
PRESTES MOTTA, F. C. G. O poder disciplinar nas organizações formais. RAE-revista de administração de empresas, v. 21, n. 4, p. 33-41, 1981.

PRESTES MOTTA, F. C. G. As empresas e a transmissão da ideologia. RAE-revista de administração de empresas, v. 24, n. 3, p. 19-24, 1984.

PRESTES MOTTA, F. C. G. Mauricio Tragtenberg: desvendando ideologias. RAE-revista de administração de empresas, v. 41, n. 3, p. 64-68, 2001.

RHINOW, G. Inovando e competindo por meio da gestão de pessoas. RAE-revista de administração de empresas, v. 41, n. 1, p. 2-7, 2001.

RIBEIRO DE ALMEIRA, M. I; TEIXEIRA, M. L. M; MARTINELLI, D. P. Por que administrar estrategicamente recursos humanos? RAE-revista de administração de empresas, v. 33, n. 2, p. 12-24, 1993.

ROMAN, D. D. Administração de pessoal científico: alguns fatores a serem considerados na supervisão de atividades técnicas. RAE-revista de administração de empresas, v. 14, n. 3, p. 73-81, 1974.

RUMBLESPERGER, F. A construção social do jovem nas revistas Exame e Você S/A. 2011. Dissertação de Mestrado apresentada à Escola de Administração de Empresas da Fundação Getulio Vargas, São Paulo, 2011.

SANTOS DE CASTRO, C. Gestão de recursos humanos no setor de telecomunicações: novas empresas, novas práticas. RAE-revista de administração de empresas, v. 45, número especial, p. 36-47, 2005.

SENNET, R. A corrosão do caráter. as consequências pessoais do trabalho no novo capitalismo. Rio de Janeiro: Record, 2004.

SIEVERS, B. Work, death and life itself: essays on management and organization. Berlin: Walter de Gruyter, 1993.

SILVA GUTIERREZ, L. H. Enfoque estratégico da função recursos humanos. RAE-revista de administração de empresas, v. 31, n. 4, p. 63-72, 1991.

SKIDMORE, T. Uma história do Brasil. São Paulo: Paz e Terra, 1998.

STEPHEN, D. W. Taking the "cross" out of cross-cultural transfer of management practice. RAE-revista de administração de empresas, v. 41, n. 4, p. 26-31, 2001.
TANURE, B. Gestão à Brasileira. 2. ed. São Paulo: Atlas, 2005.

TOTA, A. P. O imperialismo sedutor a americanização do Brasil na época da Segunda Guerra. São Paulo: Companhia das Letras, 2000.

ULRICH, D; SMALLWOOD, N; SWEETMAN, K. The leadership code: five rules to lead by. Cambridge: Harvard Business Review Press, 2009.

VASCONCELOS, F. C.; KIRSCHBAUM, C. Tropicália: manobras estratégicas em redes de músicos. $R A E-$ revista de administração de empresas, v. 47, p. 1026, 2007.

VIEIRA MANSO, E. J. Recursos humanos: avaliação do potencial. RAE-revista de administração de empresas, v. 4, n. 11, p. 123-132, 1964.

VIZEU, F. Management no Brasil em perspectiva histórica: o projeto do IDORT nas décadas de 30 e 40. 2008. Tese de Doutorado apresentada à Escola de Administração de Empresas de São Paulo da Fundação Getulio Vargas, São Paulo, 2008.

WOOD JR, T. Gestión de recursos humanos en Brasil: Tensiones e hibridismo. Academia, v. 33, p. 68-80, 2004.

WOOD JR, T; CALDAS, M. P. Adopting imported managerial expertise in developing countries: The Brazilian experience. The Academy of Management Executive, v. 16, p. 18-32, 2002.

WOOD JR, T; PAES de PAUlA, A. P. Pop management: a literatura popular de gestão no Brasil. São Paulo: FGV-EAESP, 2002. Relatório de Pesquisa n. 3, 2002.

WOOD JR, T; PAES de PAUlA, A. P. Business education in Brazil: Hybridism and tensions. In: ALON, I; MCINTYRE, J. (Ed) Business education and emerging markets: perspectives and best practices. New York: Kluwer Academic/Plenum Publishers, 2004.

WOOD JR, T; PAES de PAULA, A. P. Pop-management literature: Popular business press and management culture in Brazil. Canadian Journal of Administrative Sciences, v. 25 , p. $185-200,2008$.

WOOD JR, T; PAES de PAUlA, A. P. Pop-management literature: Popular business press and management culture in Brazil. Canadian Journal of Administrative Sciences, v. 25 , p. $185-200,2008$. 